\title{
Rural-Urban Migration and Its Consequences on Rural Children:
}

\section{An Empirical Study}

\author{
Syed Imran Ali Meerza \\ Part Time Teacher, Economics Discipline, Social Science School \\ Khulna University, Khulna-9208, Bangladesh \\ Tel: 880-1818-300746_E-mail: imran.meerza@gmail.com
}

\begin{abstract}
Rural-urban adult migration, mainly adult male migration makes heavy demand on all family members, but especially on children who are left behind in rural area to shoulder the responsibility of agriculture production and food security. Labor shortage due to rural-urban adult migration may mean that children in rural area often have to face tighter time schedules and patterns of time use and human energy inputs required in agriculture production. The study reveals the impact of rural-urban migration on rural children. In this study, sample is restricted to households that own and/or operate agricultural land in rural area. A purposive sampling is adopted to select villages and this research work covers 500 sample households. The study is based on link between rural-urban migration of adult persons and child labor in rural area. The empirical result shows that an additional rural migrant of a household increases the probability of having child worker in that household by approximately $51 \%$. In addition, this study identifies that children of migrant households receive less preventive health care in their infancy. The study also shows that an additional adult worker of a household increases the probability of having child worker in that household by $29 \%$. For this reason, this study supports the hypothesis that children are the last economic resource of a household.
\end{abstract}

Keywords: Rural-urban migration, Child farm labor, Child activities, Health input

\section{Introduction}

Migration is radically changing the socio-economic, demographic and development profile of developing countries, with far-reaching implications for agriculture-based economies. According to United Nations estimates, $50 \%$ of the projected increase in the world's urban population will come from rural-to-urban migration so that by 2025, over 1.1 billion urban people in Less Developed Regions will be rural migrants (Guerny, 1995). Clearly, the socio-economic and demographic ramifications of this massive rural exodus will have a marked impact not only on urban but also on rural areas alike. Long-term male migration from rural to urban area may fundamentally change the gender division of labor in farm households. Men may not be available for ploughing and planting which are both time and energy-intensive. For rural children, this translates into a marked increase in agricultural work.

Ashagrie (1997) estimates that about 70\% of working children of 26 developing countries are engaged in agricultural activities. The next heaviest users of child labor have much smaller shares, including manufacturing $8.3 \%$, trade $8.3 \%$ and personal services $6.5 \%$ etc. In case of Bangladesh, about 4.2 million child workers are engaged in the agriculture sector (BBS, 2003). Similarly a recent survey indicates that about $56 \%$ child workers are engaged in agricultural sector (The Daily Star, 2003).

With a diminishing supply of adult labor especially male in rural areas due to adult rural-urban migration, the farm has to depend on either children of that area or hired adult labor coming from other areas or both. Studies on several Asian countries have conclusively shown that it is primarily the young, able-bodied and better educated rural inhabitants who emigrate, leaving substantial gaps in the agricultural and rural labor force. As farming is essentially a family enterprise in most Asian countries, rural-urban migration of able-bodied young workers leaves the burden on older and children in rural areas who tend to be less productive. The long-term implications of agricultural labor force shortages are likely to result in a decline in the health status of rural families including a rise in mortality and a rise in child farm workers.

Several articles have already studied the issues of child labor and rural-urban migration separately. But the literature about the consequences of rural-urban migration on the children of origin is very limited. Among the 
most recent studies, Hildebrandt and McKenzie (2005), using a nationally representative demographic survey of Mexico, finds that children in migrant households receive less preventive healthcare facilities such as breastfeeding and vaccination than children in non-migrant households. Moreover, Salmon (2005) identifies that children are much more likely to work when they live in a household where the potential of income generation is low and where this potential has already been used up. His results are based on the Bangladesh Labor Force Survey, 2000.

The main objective of this paper is to focus on the impact of rural-urban migration on the rural children. In this case, efforts are made to find out the impact of rural urban migration on the following three aspects: (1) child farm labor, (2) child activities and, (3) child health. Further, a comparison has been made between migrant and non-migrant households by using the features: household structure and child activities.

\section{Methods}

Data for this study has collected from two villages of Khulna district of Bangladesh. These villages are Noihati and Khan Mohammad. The financial and temporal constraints are the main reasons for selecting small sample size. A purposive sampling is adopted to select villages and this study covers 500 sample households. Sample is restricted to households that own and/or operate agricultural land in rural area. To cover the information, a modified definition of households is adopted. A household is defined as a dwelling unit where a group of persons usually live together in rural area and takes food from common kitchen. It also includes those who live outside the villages but claim the household to be their own. Persons of this category work outside the villages and often send remittances. Such persons are called the migrated members of the household and such households are known as migrant household. If there is no migrated member in a household then it is called non-migrant household. The study is performed based on field level survey. In most of the cases, information has collected from the households head for reliable and desirable information. In the absence of the household head information has collected from another adult member of that household. The analysis done in this study is based on a data set with an explicit focus on rural urban migration and rural children.

\section{Results and Discussions}

The sample consists of 500 households, of which 295 households report to have at least one migrant. All households participate in a screening study in order to find out general household characteristics, such as household size and number of adult members etc. and labor profile of a household such as number of adult workers among all adult persons and number of child worker among all the children etc. Moreover, this study uses the sample of households with child worker to investigate the impact of rural-urban migration on rural children (especially on child farm labor).

\subsection{Present Circumstances of Migrant and Non-migrant Households}

ANOVA (Analysis of variance) test shows the present circumstances of migrant and non-migrant households on the basis of different characteristics like household structure and child activities etc (Table 1). The independent variable is a dummy variable taking on values of 0 or 1,0 meaning non-migrant household and 1 meaning migrant household. For each feature the dummy variable is considered as an independent variable to find out whether migrant household make any differences in that particular feature.

3.1.1 Household Structure: This study analyzes the household structure of both migrant and non-migrant household under the following heads to address its objectives.

Household size: The result shows that the estimated average household size of migrant household is higher than non-migrant households (Table 1).

Number of children: The total number of children is slightly higher in migrant household than in non-migrant households. Since null hypothesis $\left(\mathrm{H}_{0}: \beta=0\right)$ is rejected at the $1 \%$ significant level, the result indicates that the average number of children of the two categories is different (Table 1).

Percentage of adult workers among all adult: There is a huge difference between migrant and non- migrant households in case of number of adult workers among all adult persons of a household. The result shows that the mean percentage of adult workers among all adult is about $13 \%$ higher for migrant households than non- migrant households with the standard error of about $3 \%$ (Table 1).

Percentage of adult workers engaged in agriculture and stay in rural area: If the area of origin is considered then migrant households generally has less adult workers engaged in agriculture than in non-migrant households. It identifies that in case of migrant households the average percentage of adult workers engaged in agriculture and staying in rural area is $30 \%$ lower than non-migrant households (Table 1). 
Percentage of child workers among all children: Due to the shortage of adult workers in migrant households as a result of rural-urban migration, these households more often use their children as workers. The mean percentage of child workers among all the children is much higher for the migrant households (Table 1).

3.1.2 Child Activities: This research work also analyzes the child activities of rural migrant and non-migrant households of the concerned study area.

Total participation: From the table 1 it can be seen that the average percentage of household child farm workers among all child workers is high for migrant households but the percentage of wage workers of migrant households is less than non-migrant households. The table 1 also shows that the average percentage of school attainment among all the children is less for migrant households than non-migrant households.

Participation in one activity: The result shows that the percentage of only household farm worker among all the child workers of migrant households is about $57 \%$ higher than that of non-migrant households. But in case of only wage worker among all child workers and only school going children among all the children the mean percentage of migrant households is lower than non-migrant households (Table 1).

Combination of types of work: In some cases it is found that a child works as both household farm worker and wage worker. But this type of combination of work is less likely in case of migrant households than non-migrant households (Table 1).

Combination of work and school: This study tries to find out the combination of child work and school attendance. It finds that in case of combination of farm work and school attendance, the mean percentage is lower for migrant households (Table 1).

\subsection{Impact of Rural-urban Migration on Child Labor}

The goal of this section is to find out the impact of adult migration from rural to urban on rural child labor. The working sample includes households where at least one child aged between 5 to 14 years is working as a worker. Here the dependent variable is households with child worker. Several independent variables are included for analysis such as household size, age of the household head, number of adult members and number of adult migrants etc. Salmon (2005), reports that children are more likely to work when they live in a household where all the adults are working. For this reason, the hypothesis of child labor being the last economic resource of household is supported by his findings.

In present analysis, it is found that the estimated slope coefficient is 0.252 that means an additional adult worker increases the probability of having a child worker in the household by approximately $29 \%$. It also finds that the coefficient of number of rural migrants turns out to be significantly positive. Hence, an additional rural migrant of a household increases the probability of having child worker in that household by approximately $51 \%$ (Table 2).

\subsection{Impact of Rural-urban Migration on Child Activities}

This section mainly tries to find out the impact of adult rural-urban migration on activities of rural children. The dependent variables in the child activities equation are as follows: (1) a variable indicating the total number of child household farm workers among all the children of a household, (2) a variable indicating the total number of child wage workers among all the children of a household, (3) a variable indicating the total number of children going to school among all the children of a household and (4) a variable indicating the total number of children only goes to school among all the children of a household.

In case of regression 1, it is found that children are more likely to work as household farm worker when they live in a household where number of adult worker is high. Similarly the number of rural migrants of a household is highly significant in explaining the probability of child household farm worker (Table 3). From regression 2, it can be seen that there is a significant negative effect of number of rural migrants on the child wage working and the number of adult workers is not a significant determinant for child wage working (Table 3). In regression 3, all the three independent variables are not significant determinant for school attainment of children (Table 3). In case of regression 4, the result shows that the number of adult workers is not significant determinant. But the number of rural migrants has an expected negative association with the probability of school attainment of those children who are not engaged in any type of work (Table 3 ).

\subsection{Impact of Rural-urban Migration on Child Health}

The main aim of this section is to find out the impact of adult rural-urban migration on rural child health. But during survey period information has collected for only one health input and that is the number of children received vaccination. Due to the lack of data this study only shows the impact of adult rural-urban migration on 
health input. After analyzing the concerned data, it is found that children in migrant households to be significantly less likely to receive all vaccination than children in non-migrant households (Table 4). This means that children of migrant households receive less preventive health care in their infancy. One of the possible reasons for this may be a higher opportunity cost of time for migrant parents.

\section{Conclusion}

The analysis of link between adult rural-urban migration and child farm labor lends support to the hypothesis that an additional adult rural migrant of a household increases the probability of having child worker in that household. This study also finds that children are much more likely to work when they live in a household where the potential income generation is low or where this potential has already been used up. It also shows that children are more likely to work as household farm worker when they live in a household where number of adult worker is high. The number of rural migrants of a household is highly significant in explaining the probability of child farm worker in rural areas. The empirical result also shows that there is a significant negative effect of number of rural migrants on the child wage working in rural areas. From the field observation, the idea is obtained that most of the rural migrant households uses the major portion of internal remittance to buy fixed assets like land. It also has significant positive impact on the child farm labor. Further research is suggested on this particular topic, which can ensure the total welfare of working children especially in rural areas of Bangladesh. According to this study, preventive health care is less likely for children in migrant households. The empirical result suggests a need for future research into understanding the causes of lower preventive healthcare in migrant households in order to develop appropriate policy responses.

\section{References}

Ashagrie, K. (1997). Statistics on Child Labor: A Brief Report. Bulletin of Labor Statistics. ILO, Geneva, pp. 2-5.

Bangladesh Bureau of Statistics. (2003). Progotir Pathey. Ministry of Planning, Government of Bangladesh, Dhaka, Bangladesh.

Bhalotra, S. and Heady, C. (2000). Child Farm Labour: Theory and Evidence. Mimeograph, Cambridge, UK, pp. 41.

Guerny, D. (1995). Gender, migration, farming systems \& land tenure. SDWP.

Gujarati, D.N. (1998). Basic Econometrics. (3 ${ }^{\text {rd }}$ ed.). McGRAW-HILL, New York, UAS.

Hildebrandt, N. and McKenzie, J. (2005). The Effects of Migration on Child Health in Mexico. World Bank Policy Research Working Paper 3573, World Bank

Hossain, M.Z. (2001). Rural-Urban Migration in Bangladesh: A Micro-Level Study. BCSIR, Dhaka, Bangladesh. Khan, M.A. (2001). Child Labor in Dhaka City. Dhaka, Bangladesh.

Salmon, C. (2005). Child Labour in Bangladesh: Are Children the Last Economic Resources of the Household. Sage Publication, University of Savoie, France.

The Daily Star. (2003). One Sixth of Children Work. Dhaka, Bangladesh, Nov 20. 
Table 1. A comparison of household structure and child activities of migrant and non-migrant households

\begin{tabular}{|c|c|c|}
\hline Characteristics & $\begin{array}{c}\text { Coefficient } \\
(\beta)\end{array}$ & $\begin{array}{c}\text { Test } * \\
\mathbf{H}_{0}: \beta=0\end{array}$ \\
\hline Household Structure & & \\
\hline Household size & $1.251(0.343)$ & $* * *$ \\
\hline Number of children & $0.746(0.187)$ & $* * *$ \\
\hline$\%$ of adult workers among all adults & $13.041(3.088)$ & $* * *$ \\
\hline $\begin{array}{l}\% \text { of adult workers engaged in agriculture and stay in rural } \\
\text { area }\end{array}$ & $-29.946(1.938)$ & $* * *$ \\
\hline$\%$ of child workers among all children & $22.543(4.557)$ & $* * *$ \\
\hline$\frac{\text { Child activities }}{\text { a. Total participation }}$ & & \\
\hline Household farm work (in \%) & $17.205(5.952)$ & $* * *$ \\
\hline Wage work (in \%) & $-42.600(7.243)$ & $* * *$ \\
\hline $\begin{array}{l}\text { School (in \%) } \\
\text { b. Participation in one activity }\end{array}$ & $-30.254(4.895)$ & $* * *$ \\
\hline Farm work only (in \%) & $56.753(6.370)$ & $* * *$ \\
\hline Wage work only (in \%) & $-17.798(5.709)$ & $* * *$ \\
\hline $\begin{array}{l}\text { School only (in \%) } \\
\text { c. Combination of types of work }\end{array}$ & $-22.375(4.592)$ & $* * *$ \\
\hline $\begin{array}{l}\text { Household farm \& wage work (in \%) } \\
\text { d. Combination of work \& school }\end{array}$ & $-19.540(5.602)$ & $* * *$ \\
\hline Farm work \& school (in \%) & $-26.096(8.399)$ & $* * *$ \\
\hline Wage work \& school (in \%) & $-7.790(3.612)$ & ** \\
\hline
\end{tabular}

Source: Field survey, January-February, 2007

Note: $* * * \mathrm{H}_{0}$ is rejected at the $1 \%$ significance level, $* * \mathrm{H}_{0}$ is rejected at the $5 \%$ level and $* \mathrm{H}_{0}$ is rejected at the $10 \%$ level.

* Null hypothesis, $\mathrm{H}_{0}: \beta=0$ and alternative hypothesis, $\mathrm{H}_{\mathrm{A}}: \beta \neq 0$.

Parentheses indicate standard error of slope coefficient. 
Table 2. Estimation results of logit model: marginal effects of the probability of becoming a child worker

\begin{tabular}{|l|c|}
\hline Independent variables & $\begin{array}{c}\text { Households with child } \\
\text { worker }\end{array}$ \\
\hline Household size & 0.016 \\
& $(0.067)$ \\
\hline Age of the household head & 0.003 \\
& $(0.016)$ \\
\hline Number of adult members & 0.121 \\
& $(0.102)$ \\
\hline Number of adult workers among all adults & $0.252 *$ \\
& $(0.138)$ \\
\hline Number of adults engaged in rural agriculture & 0.056 \\
& $(0.212)$ \\
\hline Number of rural migrants & $0.413 * *$ \\
& $(0.170)$ \\
\hline Number of observations & 455 \\
\hline
\end{tabular}

Source: Field survey, January-February, 2007.

Note: $* * *$ indicates significant at the $1 \%$ level, $* *$ indicates significant at the $5 \%$ level and $*$ represents significant at the $10 \%$ level.

Parentheses indicate standard error of regression coefficient.

Table 3. Estimation results of logit model: marginal effects of the probability of a particular type of child activity

\begin{tabular}{|l|c|c|c|c|}
\hline Explanatory variables & $\mathbf{( 1 )}$ & $\mathbf{( 2 )}$ & $\mathbf{( 3 )}$ & $\mathbf{( 4 )}$ \\
\hline Household size & $-0.275 * * *$ & 0.139 & 0.081 & 0.018 \\
& $(0.088)$ & $(0.100)$ & $(0.082)$ & $(0.085)$ \\
Number of adult workers & $0.429 *$ & -0.091 & -0.107 & 0.201 \\
& $(0.230)$ & $(0.274)$ & $(0.220)$ & $(0.222)$ \\
Number of rural migrants & $0.626 * * *$ & $-0.868 * * *$ & -0.400 & $-0.824 * * *$ \\
& $(0.246)$ & $(0.324)$ & $(0.246)$ & $(0.250)$ \\
Constant & 0.063 & $-1.509 *$ & -0.374 & 0.328 \\
& $(0.662)$ & $(0.860)$ & $(0.667)$ & $(0.661)$ \\
\hline Number of observations & 455 & 455 & 455 & 455 \\
\hline
\end{tabular}

Source: Field survey, January-February, 2007.

Note: $* * *$ indicates significant at the $1 \%$ level, $* *$ indicates significant at the $5 \%$ level and $*$ represents significant at the $10 \%$ level.

Parentheses indicate standard error of regression coefficient.

Table 4. Estimation results of logit model: marginal effects of the probability of a child received all vaccination

\begin{tabular}{|l|c|}
\hline Explanatory variable & Child received all vaccination \\
\hline Dummy: if migrant household & $-0.503 *$ \\
& $(0.288)$ \\
Household size & $-0.194 * * *$ \\
Mother's year of schooling & $(0.073)$ \\
& $0.245 * * *$ \\
Constant & $(0.046)$ \\
& $1.158 * *$ \\
Number of observations & $(0.575)$ \\
\hline
\end{tabular}

Source: Field survey, January-February, 2007.

Note: *** indicates significant at the $1 \%$ level, ** indicates significant at the $5 \%$ level and $*$ represents significant at the $10 \%$ level.

Parentheses indicate standard error of regression coefficient. 